\title{
Update on shoulder reconstruction in BPI
}

\author{
Kazuteru Doi \\ From 10th Congress of the Asia-Pacific Federation of Societies of Surgery fo the Hand and the 6th Congress \\ of Asia-Pacific Federation of Societies of Hand Therapists \\ Kuala Lumpur, Malaysia. 2-4 October 2014
}

The shoulder joint is the foundation for excellent upper extremity function. It contributes to stability and basic movements like rotation and elevation of the arm. Shoulder fusion should not be accepted even for total palsy, and nerve repair should be recommended as long as an available donor nerve exists.

In planning the reconstructive procedure for shoulder function, accurate biomechanical analysis of individual glenohumeral (GH) and scapulothoracic (ST) joint is imperative, especially concerning serratus anterior muscle (SA) function.

Priority of nerve repair and selection of donor nerve for shoulder function are the most important key points especially in C5 7, C5 8 and total palsy depending on accompanying reconstruction of elbow and finger function including conventional nerve transfer (NT) and free muscle transfer.

Many previous articles of shoulder reconstruction with nerve repair following brachial plexus injuries were concluded from global shoulder motion that combine $\mathrm{GH}$ and ST motion, and emphasized only suprascapular nerve (SSN) repair. I emphasized SSN and long thoracic nerve (LTN) repair except in C56 palsy. The axillary nerve $(A x)$ can be ignored because simple AX palsy does not result in serious paralysis of shoulder function.

Postoperative range of shoulder motions following SSN repair, in decreasing order according to individual donor nerve was; phrenic never (PN), spinal accessory nerve (SAN), C5 root and contralateral C7 (CC7 ) root. For LTN repair; the decreasing order of post operative range of shoulder joint movements were intercostal nerve (ICN), PN, SAN, C5 root and CC7 root. PN to SSN and ICN to LTN transfer achieved the most satisfactory outcome in total palsy; however, other combinations of nerve repair and AX repair did not provide significantly better shoulder motion.

\footnotetext{
Department of Orthopaedic Surgery, Ogori Daiichi General Hospital, Ogori,
} Yamaguchi, 754 0002, Japan

Submit your next manuscript to BioMed Central and take full advantage of:

- Convenient online submission

- Thorough peer review

- No space constraints or color figure charges

- Immediate publication on acceptance

- Inclusion in PubMed, CAS, Scopus and Google Scholar

- Research which is freely available for redistribution 